\title{
Problematika Pembelajaran Daring (Online) Selama Pandemi Covid-19 Di Jurusan Analis Kesehatan Poltekkes Kemenkes Semarang
}

\author{
Ahmad Riadi ${ }^{1 *}$, Widodo ${ }^{1}$, Devi Etivia Purlinda ${ }^{1}$ \\ 1Poltekkes Kemenkes Semarang, Indonesia \\ *Korespondensi: ahmadriadi41@gmail.com
}

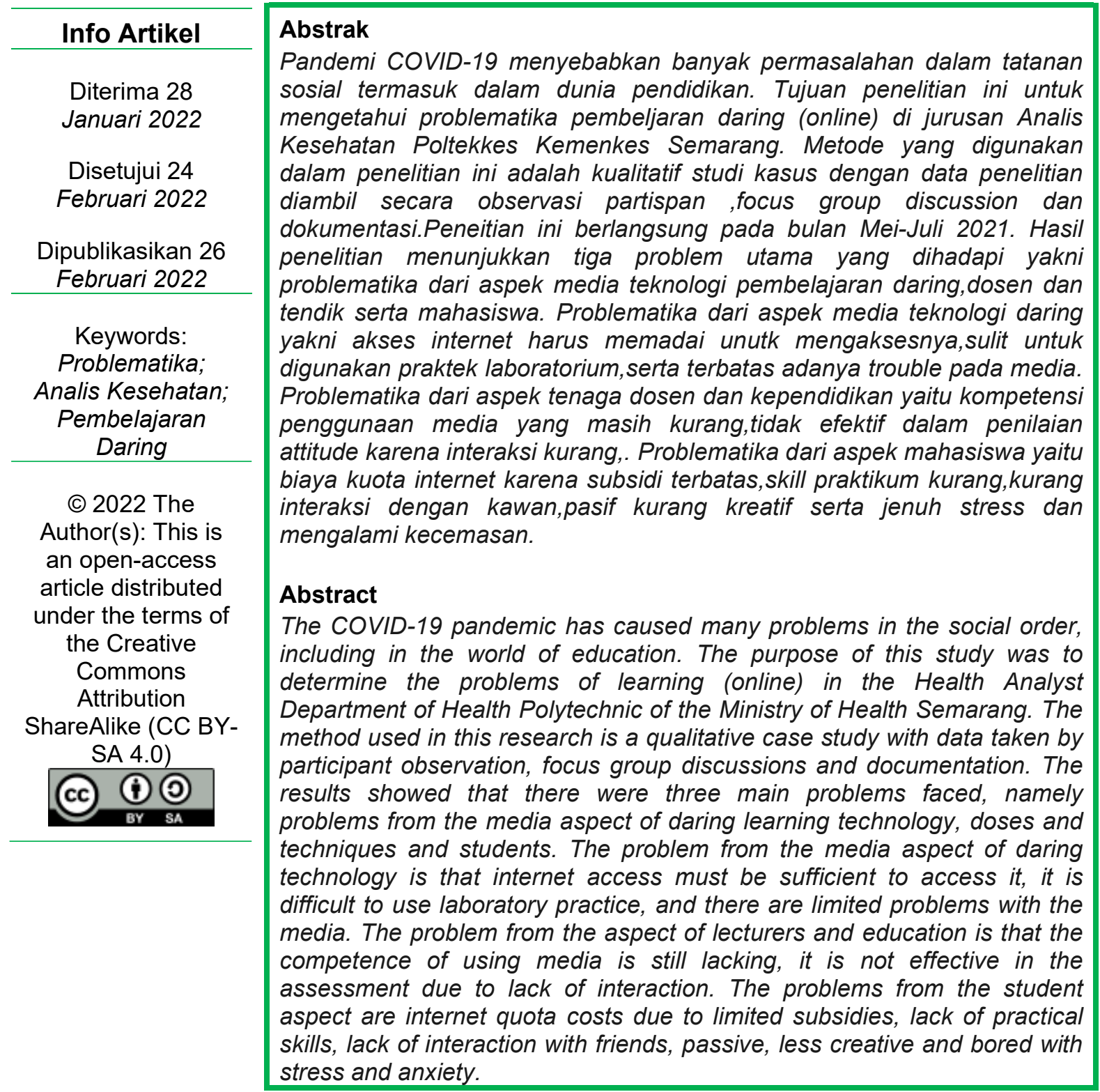




\section{Pendahuluan}

Menurut UNESCO diseluruh dunia sekitar 1,3 Milliyar pelajar dan mahasiswa tidak dapat mendapatkan Pendidikan secara maksimal selama pandemi covid-19. Hal ini menjadi perhatian bagi negara-negara didunia untuk memberikan fasilitas pendidikan kepada pelajar untuk mendapatkan Pendidikan seperti komputer, ketersediaan internet dan E-book serta penyediaan aplikasi pembelajaran online (Schleicher, 2020)

Di indonesia diterapkan pembelajaran daring online berdasarkan intruksi SKB 3 Menteri No 4 Tahun 2020 bahwa dalam masa pandemi covid-19 maka semua aktivitas Pendidikan baik di daerah provinsi sampai pusat untuk melaksanakan pembelajaran secara daring online atau pembelajaran jarak jauh untuk mencegah penyebaran covid-19 di lingkungan Pendidikan namun hal tersebut perlu mendapatkan dukungan dari orang tua dan pemerintah setempat (Kesehatan et al., 2021)

Universitas adalah instansi Pendidikan yang paling berdampak meminta kepada dosen, mahasiswa dan tutor untuk menggunakan media online dan memastikan pembelajaran tidak terganggu. Namun hal ini menjadi tantangan tersendiri bagi aktivitas pembelajaran di lingkungan pendidikan diantaranya ketidakmampuan beradaptasi dengan perubahan lingkungan belajar yang baru, Pendidik memberi tugas yang banyak kepada siswa, Kesehatan pribadi terkait stress dan kecemasan (Al-Kumaim et al., 2021)

Instansi Pendidikan nampaknya masih mempunyai problem dalam menerapkan kebijakan pemerintah. Problem yang mendasar dalam penerapan belajar daring utamanya terkait masalah fundamental antara lain jaringan internet, keterbatasan aplikasi pembelajaran daring, serta kendala dalam hal pelayanan pembelajaran (Hutauruk \& Sidabutar, 2020).

Salah satu hal yang paling mendasar dalam masalah pembelajaran daring (online) adalah gagap teknologi. Perubahan model pembelajaran dari luring menjadi daring membuat civitas akademika memutar otak untuk menguasai teknologi sementara mereka terbatas oleh kompetensi, Ekonomi ,sarana dan prasarana serta usia pendidik yang sudah tua (Mulawarman, 2020)

Pandemi pun berdampak pada system pembelajaran di kampus Poltekkes Kemenkes Semarang terutama di Jurusan Analis Kehatan.Hal ini dapat di lihat melalui pengamatan langsung yang awalnya pembeljaran dilakukan dengan tatap muka kemudian saat ini di laksanakan dengan daring online.Pembelajaran daring dilaksanakan dengan menggunakan aplikasi web helti dan zoom meeting namun bukan berarti tampa kendala,ada banyak kendala atau problematika pembelajaran daring diantaranya mengenai kuota internet, kompetensi dosen ,beban psikologis mahasiswa dan dosen. Dari data dan survey awal yang di lakukan oleh peneliti bahwa terdapat beberapa problematika pembelajaran daring di jurusan analis Kesehatan maka peneliti bermaksud untuk melakukan penelitian dengan judul Problematika Pembelajaran Daring (Online) Selama Pandemi Covid-19 Di Jurusan Analis Kesehatan Poltekkes Kemenkes Semarang.

\section{Metode Penelitian}

Metode yang di gunakan dalam penelitian ini adalah Penelitian Kualitatif studi kasus. Studi kasus merupakan Penelitian metode studi kasus adalah 
dimana peneliti melakukan eksplorasi secara mendalam terhadap program, kejadian, proses, aktivitas, terhadap satu atau lebih orang. Suatu kasus terikat oleh waktu dan aktivitas dan peneliti melakukan pengumpulan data secara mendetail dengan menggunakan berbagai prosedur pengumpulan data dan dalam waktu yang berkesinambungan (Sugiyono 2016:17). Studi kasus dianggap metode yang paling fleksibel ,menantang dan memiliki kajian yang mendalam terhadap suatu kasus (Cresswell John W \& Poth Cheryl N, 2018:156). Penelitian ini berlagsung pada bulan Mei-Juli 2021 di Jurusan Analis Kesehatan Poltekkes Kemenkes Semarang.

Teknik Pengumpulan data yang digunakan dalam penleitian ini yakni observasi partisipan,Focus Group Discussion (FGD),dan dokumentasi. Obervasi partisipan adalah peneliti ikut serta terlibat dalam pengajaran. Focus group discussion (FGD) di laksanakan di akhir semester yang menjadi kegiatan diskusi antara dosen dan mahasiswa. Sumber data yang digunakan ada 2 yakni sumber data primer dan sekunder. Sumber data primer adalah sumber data yang didapatkan sendiri oleh peneliti melalui pengajaran,FGD atau wawancara langsung dan sumber data sekunder di dapat melalui literatur ilmiah.

Validitas data mengunakan triagulasi data yakni membandingkan antara hasil observasi, Focuss Group Discussion (FGD) dan Kondisi yang ada .1). Reduksi data, Memilih dan menyeleksi data yang didapatkan kemudian diolah dan memfokuskan semua data supaya lebih bermakna.2).Penyajian Data,data yang telah dikumpulkan dipahami ,di ekplorasi ,dianalisis dan disajikan.3) Kesimpulan, menyimpulkan data yang didapatkan dan di deksripsikan berdsarkan focus penelitian.

\section{Hasil}

Pandemi covid-19 menyebabkan perubahan dalam tatanan sosial bukan hanya di masyarakat tapi juga berdampak pada aktivitas pengajaran di lingkungan Pendidikan terutama di lingkup perguruan tinggi termasuk di Poltekkes Kemenkes Semarang. Poltekkes Semarang merupakan salah satu kampus yang berada dibawah kementerian Kesehatan juga ikut aktif terlibat dalam penerapan proses belajar daring akibat pandemi covid dibawah ini hasil observasi partisipan dan focus group discussion (FGD) Sarasehan di lingkungan Analis Kesehatan

Aktiviatas pembelajaran daring (online) di jurusan analis Kesehatan menggunakan Web Helti dan Zoom meeting. Web HELTI sendiri adalah suatu web yang di kembangkangkan oleh Poltekkes Kemenkes Semarang untuk memfasilitasi pembelajaran daring sebelum pandemi covid-19 dan di maksimalkan penggunaannya saat pandemi covid namun masih mempunyai banyak kendala diantara seperti diskusi sarasehan dengan mahasiswa di bawah ini “

Saat mengerjakan ujian ada kalanya helti loading lumayan lama padahal jaringan sudah memadai

Sering eror jika dilakukan Bersama sama atau secara tiba tiba pada server

Aplikasi zoom meeting adalah aplikasi yang juga di digunakan dalam pembelajaran online oleh civitas akademi jurusan analis Kesehatan disaat pandemi covid-19 ini. Namun aplikasi ini pun mempunyai kendala yang dikeluhakan oleh mahasiswa dan dosen antara lain disebutkan dalam diskusi zoom : 
Posisi tulisan hadir dan izin sering kali berbeda di absen teori dan praktek, dikhawatirkan ada mahasiswa yang salah pencet karena hal tersebut

Nilai absensi tidak muncul ke nilai, terkadang absensi eror dan tidak bisa diakses

Pada saat UTS, helti mengalami down sehingga jawaban dari UTS yang belum sempat diperiksa kembali langsung terkumpul karena kehabisan waktu

"Pembelajaran praktek di maksimal di zoom meeting sehingga dosen membebani banyak tugas kepada mahasiswa'

zoom meeting membutuhkan jaringan yang memadai untuk di akses oleh mahasiswa sementara tidak semua mahasiswa tinggal di daerah perkotaan"

dosen mengeluhkan banyak mahasiswa yang offcamera saat pembelajaran online

Pandemi covid-19 juga membuat tenaga dosen dan pendidik untuk beradaptasi dengan cepat dengan system pembelajaran daring, dari observasi yang telah dilakukan oleh peneliti menemukan bahwa mayoritas dosen masih kesulitan dalam adapatasi pembeljaran baru melalui jaringan online hal ini membuat pembelajaran menjadi tidak maksimal terutama pada pembelajaran praktek laboratorium, berikut beberap fakta yang di temukan oleh peneliti :

Sangat sulit mas karena praktek kan pakai alat laboratorium sementara klo melalui you tube partisipatif mahaiswa kurang

Ketika mahasiswa mempresentasikan, dosen tersebut tidak memberikan koreksi yang benar, sesuai dengan kurikulum yang diajarkan. Sehingga terkadang mahasiswa bingung dengan materi yang digunakan itu yang mana; terkadang materi yang digunakan untuk ujian jauh berbeda dengan yang disampaikan ketika mengajar sehingga mahasiswa mendapat nilai yang tidak memuaskan.

akses internet kadang tidak stabil sangat sulit untuk melakukan proses belajar mengajar efektif

ada mahasiswa yang pintar hack Web Helti

Hal yang sama juga dirasakan oleh mahasiswa jurusan analis Kesehatan,mahasiswa belum siap dalam menerima pembelajaran online sehingga pembelajaran tidak efektif. Ada beberapa kendala yang di temukan oleh peneliti digambarkan dalam deksripsi sebagai berikut "

Sebagai mahasiswa tk2 yang belum pernah datang kekampus dan belum pernah praktik secara langsung, saya merasa bahwa keberhasilan seorang mahasiswa itu ada pada praktika, karena dengan berjalannya hampir 2 tahun ini jujur saya pribadi merasa tidak mendapatkan apa apa dan meskipun praktik dari rumah, alat praktik harus mengeluarkan modal sendiri'"'Pembagian kuota internet harus lebih terti."

Saya harap jadwalnya jangan terlalu padat dan tugasnya jangan terlalu memberatkan

Untuk penugasan saya rasa terlalu banyak, soalnya kadang ada tugas terstruktur, tugas dari teori dan praktek yang diganti dengan penugasan dan dengan deadline yang hampir bersamaan. Jadi kami sebagai mahasiswa kadang kualahan.

Harusnya ada pembelajaran luring ,daring membuat kami meras kurang skill, jenuh, bosan dan stress pak. 
'Kami bingung harus bagaimana jika online begini trs skill kami kurang apalagi kita tk 3 DIII TLM ini akan ada tawaran kegiatan PADINAKES bagi yg terpilih, kalau skill kita kurang bagaimana kita bisa menolong orang2 di pedalaman sana. Mohon utk ditindak lanjuti'

\section{Pembahasan}

\subsection{Problematika Media teknologi pembelajaran daring (online)}

Peneliti menemukan bahwa ada Dua aplikasi yang digunakan oleh civitas akademika di jurusan analis Kesehatan Poltekkes Kemenkes Semarang yakni aplikasi Zoom meeting dan Web Helti. Aplikasi ini mempunyai problematika yang keluhkan oleh mahasiswa maupun oleh dosen sebagai contoh zoom meeting membutuhkan jaringan yang memadai untuk di akses, kuota internet, zoom meeting terbatas dalam praktek begitu pula aplikasi berbasis Web Helti yang mempunyai kekurangan.

Aplikasi zoom meeting merupakan aplikasi yang saat ini paling banyak digunakan di lingkungan Pendidikan. Aplikasi ini mempunyai fasilitas berupa video serta slide show materi pdf ,word maupun image namun belum efektif digunakan unutk pembelajaran praktek laboratorium sementara aplikasi berbasis web Helti masih dalam tahap penyempurnaan

Aplikasi dengan zoom meeting atau aplikasi lainnya seharusnya dapat menjadi wadah yang bagus dalam menunjang proses pembelajaran namun dengan adanya beberapa persyaratan dalam pemakain membuat pembelajaran menjadi tidak efektif diantaranya seperti permasalahan jaringan,kuota serta kempauan dosen dan mahasiswa mengatasi kejenuhan dan stress (Farfar, 2021)

Zoom meeting juga harus di dukung oleh perangkat teknologi yang memiliki spesifikasi baik karenan jika hal itu di abaikan maka akan berdampak pada kualitas video comference buruk ,audio menjadi tidak jelas namun zoom meeting juga mempunyai dampak positif antara lain minat dan motivasi belajar menjadi tinggi, interaksi aktif serta kemudahan akses informasi (Kim, 2020)

Zoom meeting di jurusan analis kesehatan di fasilitasi oleh pihak kampus dengan fasilitas zoom meeting premium . Aplikasi tersebut masih kurang efektif karena Poltekkes Semarang merupakan kampus vocational yang $60 \%$ pengajaran dalam bentuk praktek. Aplikasi zoom dan web tidak mempunyai pengaruh yang efektif dalam meningkatkan nilai dan minat mahasiswa dalam belajar. Mahasiswa cepat jenuh dan bosan karena pengajaran hanya bersifat ceramah melalui ppt dan video sehingga dosen diharapkan untuk melakukan variasi media pengajaran misanya dalam bentuk animasi (Nuriansyah, 2020)

Perubahan pembelajaran jarak jauh yang di lakukan secara daring (online) membutuhkan waktu adaptasi bagi civitas akademika misalnya dosen dan pendidik di lingkungan Jurusan Analis Kesehatan. Hal ini disebabkan karena dibutuhkan instumen penunjang terlaksananya pembelajaran online namun ditemukan kendala dalam dari dosen maupun pendidik seperti zoom meeting dan web Helti tidak efektif dalam praktek laboratorium, Mahasiswa lebih banyak diam dan tidak aktif dalam pembelajaran. Hal ini tidak sejalan dengan penelitian yang di laksanakan di universitas Muhammadiyah UHAMKA ditemukan fakta bahwa mayoritas mahasiswa menyukai pembelajaran daring online dengan alasan lebih kreatif dalam pembelajaran ,memiliki ekmajuan dalam bidang teknologi serta variasi 
konten pembelajaran sementara yang menolak beralasan informasi dan proses belajar lebih mudah di pahami saat tatap muka (Susanti \& Suswandari, 2021)

\subsection{Problematika Pembelajaran Daring terhadap Tenaga Dosen dan Kependidikan}

Problematika bukan hanya pada media yang digunakan untuk pembelajaran online tetapi juga pada tenaga dosen dan pendidik. Perubahan proses pembelajaran yang cepat memaksa tenaga dosen dan kependidikan untuk beradaptasi dengan cepat dengan situasi yang terjadi. Tantangan yang dihadapi oleh dosen dan tenaga kependidikan pun bervariasi anatara lain terbatasnya interaksi sehingga system pembelajaran dominan system penugasan, rasa cemas, jenuh dan stress serta kompetensi dalam penggunaan media online (Jiwandono et al., 2021)

Dosen dan tendik di jurusan analis kesehatan poltekkes kemenkes semarang merasa dalam pembelajaran online lebih butuh waktu dan tidak efisien. Dosen mengeluhkan fasilitas sarana yang kurang memadai, proses belajar yang tidak efektif dan keterkaitan secara psikologi menjadi berkurang padahal hal tersebut sangat penting dalam proses pembelajaran. Dosen dituntut untuk membuat metode belajar daring yang mampu memotivasi mahasiswa untyuk terlibat dalam pembelajaran sementara di lain sisi pembelajaran daring membutuhkan lebih banyak waktu.

Ada beberapa dosen yang merasa bahwa perlunya pelatihan atau workshop untuk meningkatkan kompetensi dosen dengan metode pembelajaran yang berubah secara mendadak namu hal tersebut tidak bisa dilakukan karenan kurangnya waktu luang,fasilitas internet dan metode pengajaran yang tidak mendukung menyebabkan pembelajaran yang dilakukan menjadi tidak efektif (ÖZÜDOĞRU, 2021)

Dalam hal penilaian pun masih menjadi problem dalam pembelajaran daring,ada banyak varibael yang dinilai sebagai seorang dosen antara lain kognitif,attitude,dan psikomotor sementara dengan dilaksanakannya pembelajaran daring sulit di evaluasi sebagai conto untuk melihat attitude mahasiswa dalah hal sederhana ketika diberi penugasan,dosen tidak bisa memantau bahwa apakah tugas dikerjakan sendiri,mencontek ,plagiasi dll (Sidebang et al., 2021)

\subsection{Problematika Pembelajaran Daring terhadap Mahasiswa}

Penelitiaan ini juga menemukan bahwa selama pembelajaran daring (online) sangat berdampak terhadap mahasiswa jurusan Analis Polekkes Kemenkes Semarang. Hal ini dapat di lihat dengan banyakya laporan masukan dan kritikan selama saresehan berlangsung. Aspek pembelajaran daring yang paling disoroti terutama karena menjadikan mahasiswa sebagai pusat pembelajaran atau di kenal dengan student learning center yang memungkinkan bagi dosen untuk memberikan penugasan serta membuat media pembelajaran (Firman \& Rahayu, 2020)

Problematika pembelajaran daring pada mahasiswa yang muncul selama pembelajaran daring berupa kesiapan mahasiswa, banyaknya tugas, waktu yang mepet, Penguasaan media pembelajaran daring, jumlah kuota dan kondissi sinyal. Adanya kebijakan pemerintah membatasi proses pembelajaran serta tidak adanya kepastian yang didapatkan oleh mahasiswa tentang pembelajaran luring membuat 
dampak yang sangat besar bagi mahasiswa yang utamanya berasal dari pedalaman yang kekurangan infrakstruktur dan daya dukung lainnya (Vibriyanti, 2020)

Mahasiswa adalah salah satu civitas yang paling berdampak dengan adanya pandemi covid-19 yang sebelumnya perkuliahan dilaksanakan secara luring (luar jaringan) menjadi daring (Dalam jaringan). Peneliti melihat bahwa selama perkuliahan daring (online) skill mahasiswa dalam bidang praktek berkurang dibuktikan dengan wawancara pihak rumah sakit maupun PMI Sebagai lahan praktek.Penelitian di Universitas Sebelas Maret menyebutkan bahwa pembelajaran daring mempunyai dampak terhadap mahasiswa diantaranya mahasiswa bingun dengan pembelajaran daring,mahasiswa menjadi pasif,kurang kreatif ,tidak produktif dan penumpukan informasi yang kurang bermamfaat serta mahasiswa mengalami stress (Argaheni, 2020)

Pembelajaran daring (online) menurunkan minat belajar karena mudah menjadi bosan saat belajar daring,pembelajaran kurang menarik, butuh kuota internet, spesifikasi alat yang digunakan tidak mendukung aplikasi media online serta kurangnya pengetahuan akan teknologi. Hal ini berdampak pada pembelajaran menjadi tidak efektif dan aktif

Namun dampak terhadap mahasiswa tidak selalu berdampak negative ada banyak hal-hal positif juga di rasakan oleh mahasiswa diantaranta mahasiswa yang menyenangi belajar mandiri sangat antusias dengan pembelajaran online ,mahasiswa menjadi lebih kreatif, lebih hemat dalam biaya karena perkuliahan dilakukan dirumah sementara kuota di subsidi serta mereka mampu memamfaatkan waktu menjadi lebih efisien (Harapani, 2021)

\section{Kesimpulan}

Problematika pembelajaran daring di Jurusan Analis Kesehatan Poltekkes Kemenkes Semarang dapak di lihat dari 3 aspek antara lain teknologi media pembelajaran daring, dosen dan tenaga kependidikan dan mahasiswa. Problematika dari aspek media pembelajaran online yang diguanakan zoom meeting dan web helti yaitu akses internet harus memadai unutk mengaksesnya,sulit untuk digunakan praktek laboratorium,serta terbatas adanya trouble pada media. Problematika dari aspek tenaga dosen dan kependidikan yaitu kompetensi penggunaan media yang masih kurang,tidak efektif dalam penilaian attitude karena interaksi kurang.. Problematika dari aspek mahasiswa yaitu biaya kuota internet karena subsidi terbatas,skill praktikum kurang,kurang interaksi dengan kawan,pasif kurang kreatif serta jenuh stress dan mengalami kecemasan

\section{Ucapan Terima Kasih}

Peneliti mengucapkan terima kasih kepada Ketua Jurusan Analis Kesehatan serta rekan Dosen dan Tenaga Kependidikan, Sub unit IT serta mahasiswa yang mendukung dan ikut terlibat dalam penelitian mandiri ini .

\section{Daftar Pustaka}

Al-Kumaim, N. H., Alhazmi, A. K., Mohammed, F., Gazem, N. A., Shabbir, M. S., \& Fazea, Y. (2021). Exploring the impact of the covid-19 pandemic on university students' learning life: An integrated conceptual motivational model for sustainable and healthy online learning. Sustainability (Switzerland), 13(5), 1- 
21. https://doi.org/10.3390/su13052546

Argaheni, N. B. (2020). Sistematik Review: Dampak Perkuliahan Daring Saat Pandemi COVID-19 Terhadap Mahasiswa Indonesia. PLACENTUM: Jurnal Ilmiah Kesehatan Dan Aplikasinya, 8(2), 99. https://doi.org/10.20961/placentum.v8i2.43008

Farfar, G. (2021). Efektifitas Penggunaan Aplikasi Zoom Meeting dalam Pembelajaran. ISTORIA: Jurnal Pendidikan Dan Sejarah, 17(1), 1-5.

Firman, F., \& Rahayu, S. (2020). Pembelajaran Online di Tengah Pandemi Covid19. Indonesian Journal of Educational Science (IJES), 2(2), 81-89. https://doi.org/10.31605/ijes.v2i2.659

Harapani, A. (2021). Pengaruh Kuliah Daring Saat Pandemi Covid-19 Terhadap Kemampuan Mahasiswa. Jurnal Kedokteran Universitas Lambung Mangkurat, 3-4.

Hutauruk, A., \& Sidabutar, R. (2020). Kendala pembelajaran daring selama masa pandemi di kalangan mahasiswa pendidikan matematika: Kajian kualiatatif deskriptif. Journal of Mathematics Education and Applied, 02(01), 45-51. https://jurnal.uhn.ac.id/index.php/sepren/article/view/364

Jiwandono, I. S., Setiawan, H., Oktaviyanti, I., Rosyidah, A. N. K., \& Khair, B. N. (2021). Tantangan Proses Pembelajaran Era Adaptasi Baru. Jurnal Pendidikan Dan Ilmu Pengetahuan, 21(1), 43.

Kesehatan, M., Menteri, D. A. N., Negeri, D., Kesehatan, M., Menteri, D. A. N., \& Negeri, D. (2021). Keputusan Bersama Menteri Pendidikan Dan Kebudayaan, Menteri Agama, Menteri Kesehatan, Dan Menteri Dalam Negeri Republik Indonesia. 7.

Kim, H. (2020). The Efficacy of Zoom Technology as an Educational Tool for English Reading Comprehension Achievement in EFL Classroom. International Journal of Advanced Culture Technology, 8(3), 198-205. https://doi.org/10.17703/IJACT.2020.8.3.198

Mulawarman, W. G. (2020). Persoalan Dosen dan Mahasiswa Masa Pandemik Covid 19: Dari Gagap Teknologi Hingga Mengeluh Boros Paket Data. Prosiding Seminar Nasional Hardiknas, 37-46.

Nuriansyah, F. (2020). Efektifitas Penggunaan Media Online Dalam Meningkatkan Hasil Belajar Pada Mahasiswa Pendidikan Ekonomi Saat Awal Pandemi Covid-19. Jurnal Pendididikan Ekonomi Indonesia, 1(2), 61-65. https://ejournal.upi.edu/index.php/JPEl/article/view/28346

ÖZÜDOĞRU, G. (2021). Problems faced in distance education during Covid-19 Pandemic. Participatory Educational Research, 8(4), 321-333. https://doi.org/10.17275/per.21.92.8.4

Schleicher, A. (2020). The impact of COVID-19 on education: Insights from education at a glance 2020. OECD Journal: Economic Studies, 1-31. https://www.oecd.org/education/the-impact-of-covid-19-on-education-insightseducation-at-a-glance-2020.pdf

Sidebang, R., Napitupulu, R., \& Simaremare, H. (2021). Daring Pendidikan Pembelajaran Tematik Jurusan Pendidikan Guru Sekolah Dasar ( Pgsd ) Di 
Universitas Hkbp Nommensen Pematangsiantar.

Susanti, E. N., \& Suswandari. (2021). Efektivitas Pembelajaran Daring pada Mahasiswa Pendidikan Ekonomi UHAMKA di Masa Pandemi COVID 19. Jurnal Penelitian Dan Penilaian Pendidikan, 3(2), 32-43. https://doi.org/10.22236/jppp.v3i2.6919

Vibriyanti, D. (2020). Kesehatan Mental Masyarakat: Mengelola Kecemasan Di Tengah Pandemi Covid-19. Jurnal Kependudukan Indonesia, 2902, 69. https://doi.org/10.14203/jki.v0i0.550 